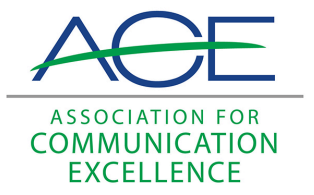

Journal of Applied Communications

\title{
Community-Based Grazing Marketing: Barriers and Benefits Related to the Adoption of Best Management Practices in Grazing Systems
}

\author{
Audrey E. H. King \\ Lauri M. Baker \\ Peter J. Tomlinson
}

Follow this and additional works at: https://newprairiepress.org/jac c) (i) (2)

This work is licensed under a Creative Commons Attribution-Noncommercial-Share Alike 4.0 License.

\section{Recommended Citation}

King, Audrey E. H.; Baker, Lauri M.; and Tomlinson, Peter J. (2017) "Community-Based Grazing Marketing: Barriers and Benefits Related to the Adoption of Best Management Practices in Grazing Systems," Journal of Applied Communications: Vol. 101: Iss. 1. https://doi.org/10.4148/1051-0834.1013

This Research is brought to you for free and open access by New Prairie Press. It has been accepted for inclusion in Journal of Applied Communications by an authorized administrator of New Prairie Press. For more information, please contact cads@k-state.edu. 


\title{
Community-Based Grazing Marketing: Barriers and Benefits Related to the Adoption of Best Management Practices in Grazing Systems
}

\author{
Abstract \\ Environmental impacts of less than optimal grazing management choices can be intense and \\ widespread. Improved communication of responsible grazing practices known as best management \\ practices (BMPs) may increase adoption of these practices and increase sustainability of grazing \\ systems. Community-based social marketing (CBSM) is a tool that can be used by communicators to \\ generate behavior changes. This strategy emphasizes the identification of barriers to goal behaviors and \\ the development of strategies to overcome them. This study sought to identify barriers and benefits \\ associated with the adoption of grazing BMPs. Barriers identified include water availability and quality, \\ and leasing and renting land. Benefits identified were increased resiliency through rotational grazing, \\ improved watering and burning practices.
}

\section{Keywords}

Opinion Leadership, Social Influence, Social Media, Water Quality 


\title{
Community-Based Grazing Marketing: Barriers and Benefits Related to the Adoption of Best Management Practices in Grazing Systems
}

\author{
Audrey E. H. King, Lauri M. Baker, and Peter J. Tomlinson
}

\begin{abstract}
Environmental impacts of less than optimal grazing management choices can be intense and widespread. Improved communication of responsible grazing practices known as best management practices (BMPs) may increase adoption of these practices and increase sustainability of grazing systems. Community-based social marketing (CBSM) is a tool that can be used by communicators to generate behavior changes. This strategy emphasizes the identification of barriers to goal behaviors and the development of strategies to overcome them. This study sought to identify barriers and benefits associated with the adoption of grazing BMPs. Barriers identified include water availability and quality, and leasing and renting land. Benefits identified were increased resiliency through rotational grazing, improved watering and burning practices.
\end{abstract}

\section{KEY WORDS}

Agriculture, Barriers, Best Management Practices, Community-based Social Marketing, Grazing, Sustainability

\section{INTRODUCTION}

Communicators have been facilitating the adoption of sustainable behavior for years. Community-based social marketing (CBSM) is one tool communicators use to generate environmental behavior changes (McKenzie-Mohr, 2000). CBSM involves: 1) selecting the behavior to promote; 2 ) identifying the barriers and benefits associated with the behavior selected; 3) developing a strategy with behavior-change tools to address the barrier; 4) piloting the plan; and 5) evaluating the plan once implemented (McKenzie-Mohr, 2011). CBSM helps motivate people to make changes towards more sustainable behaviors through strategic plans involving social networks and manageable steps. The purpose of this study was to address the second step in CBSM through the identification of barriers and benefits to best management practice (BMP) adoption.

CBSM may provide means to increase adoption of BMPs in agriculture. Agriculture has the potential to have both a positive and negative effect on its surrounding environment, communities, and people. BMPs for agricultural producers have been developed from many years of research and are intended to minimize potential environmental impacts of various agricultural production practices while increasing the profitability of producers' operations (Paudel, Gauthier, Westra, \& Hall, 2008). In contrast, poor stewardship of grazing lands and farm ground can result in water pollution, soil erosion, and land degradation. Increased adoption of BMPs in an area benefits the environment, citizens, and economies of the region. 


\section{CONCEPTUAL FRAMEWORK}

\section{Community-based social marketing.}

Information-based campaigns assume that a behavior change will take place if enough information is provided. However, education alone has little to no effect on creating long-lasting behavior changes (McKenzie-Mohr, 2000). Communitybased social marketing (CBSM) has proven successful at generating socially desirable behavior change. CBSM pulls from social psychology research that has established behavior change campaigns are most effective when targeted at the community level, while focusing on the barriers associated with adopting the desired behavior (Pallack, Cook, \& Sullivan, 1980). Behavior-change initiatives are more effective when they come from the community level with personal contact rather than the global level with little personal contact (McKenzie-Mohr, 2011). CBSM does not rely as heavily upon mass-media advertising as social marketing. CBSM is frequently used to encourage behavior change pertaining to environmental issues like decreasing waste to landfills, saving energy, and conserving water (McKenzie-Mohr, 2011; Vigen \& Mazur-Stommen, 2012).

In order to create a lasting behavior change, it is important to execute CBSM in the proper order. After a behavior has been selected, barriers should be identified. Despite the importance of correctly identifying barriers to behavior adoption for CBSM to be successful, program planners often skip this step (Pallack, Cook, \& Sullivan, 1980). Some of the most common reasons for skipping this essential step are that program planners think barriers are already known, and time and funding constraints prevent adequate barrier research (Pallack et al., 1980). Identifying barriers begins with reviewing relevant literature related to the selected behavior. Next, research should be conducted to understand attitudes about the behavior (McKenzie-Mohr, 2000). This can be done through focus groups or interviews.

Once barriers have been identified, the strategies developed to address these will impact the effectiveness of the behavior-change message. Strategies are more likely to succeed when communication is concrete and personalized to the audience (McKenzie-Mohr, 2011). The more vivid information is the more it stands out against all the other information bombarding audiences daily (McKenzie-Mohr, 2011). When audiences are analyzed, communicators should consider all people affected by the message. Multiple audiences should be considered when messages are developed (McKenzie-Mohr, 2011).

The source of communication also influences the effectiveness of the message (McKenzie-Mohr, 2011). As Extension agents are seen as credible information sources already engaged within their communities they are potential liaisons for BMP communication (Patton \& Blaine, 2001). Once initial contact had been made, CBSM calls for developing a strategy, by using several options, such as commitment seeking, delivering prompts, and establishing social norms (McKenzieMohr, 2011). CBSM focuses on utilizing connections people already have, and using those to change social norms and promoting sustainable behaviors, such as BMPs (McKenzie-Mohr, 2011). Therefore, pre-existing relationships with Extension professionals make agents an effective message source.

\section{State of the Industry}

Agriculturists manage pastures and rangeland in all 50 states (Natural Resources Conservation Services, n.d.). Range and pasture lands make up over $27 \%$ (528 million acres) of the total acreage of the contiguous 48 states (NRCS, n.d.) with more total acreage than both forest and cropland. According to the 2012 Census of Agriculture, there were 22.1 million acres of grazing lands in Oklahoma (2014). Grazing lands in Kansas were equal to 16.2 million acres (USDA, 2014). Effective management is related to sustainability. Cox (2013) defined sustainability as a three-legged stool, where each leg must be considered for sustainability to be achieved, the three legs to consider are environment, economics, and equity or social justice. Proper management of grazing lands is important to prevent degraded land quality (Ohlenbusch \& Watson, 1994), which affects both the environment and economics. 
King et al.: Community-Based Grazing Marketing: Barriers and Benefits Related

The drought of 2011 and 2012 left pasture and rangeland across the Southern Great Plains overgrazed and damaged (USDA, 2013). The following year, 2013, marked the eighth year of decreasing beef cow numbers in the United States. By 2014, drought conditions negatively affected the quality and quantity of forage available for cattle production (Hurt, 2014), increased feed prices and caused beef cow numbers to reach the lowest since 1951. In the Southern Great Plains alone, there was a loss of 1.6 million head of cattle (Hurt, 2014). In 2011 alone, drought resulted in more than $\$ 1.6$ billion lost from the agricultural sector in Oklahoma, with over $\$ 6.6$ million of loss in the livestock sector (Wessler, 2011). The areas affected by this drought encompassed many different forage types, regions, and people. Negative impacts to both environmental and economic aspects of sustainability during periods of drought could have been partially mitigated through the adoption of BMPs.

Public perception of agriculture has changed from a reputation of good land and animal stewardship to that of pollution and abuse (Rahelizatovo \& Gillespie, 2004) with the public becoming increasingly concerned about the effect of modern agriculture on the environment (Wachenheim \& Rathge, 2000). The degraded land appearance caused by the droughts did not help improve the public image of agriculturalists. Nevertheless, members of the agricultural community, continue to view themselves as good stewards (Rahelizatovo \& Gillespie, 2004).

\section{Best Management Practices}

Following the negative consequences of environmental degradation during the Dust Bowl in 1934-1940, farmers and ranchers began to understand the importance of preserving the land for future use. BMPs are backed by research as the most effective, environmentally sustainable, and long-term economically efficient way to manage an operation (Feather \& Amacher, 1994; Gillespie, Kim, \& Paudel, 2007; Paudel et al., 2008). BMP adoption increases the resiliency in not only individual producers' operations, but also the overall sustainability of the environment, cattle industry, and the economies of rural areas. Yet, scientists, policy makers, and Extension professionals have all conveyed frustration at the low level of BMP adoption among farmers and ranchers (Pannell et al., 2006).

BMPs specifically suggested in the Southern Great Plains for increased sustainability of grazing based beef cattle production are rotational grazing (moving cattle periodically to protect grass), prescribed burning of grass, setting proper stocking rates of cattle, managing drought, and implementing improved watering systems. These practices increase the profitability of operations and decrease the environmental impact.

\section{BMP Adoption}

Several Extension documents reviewed for this study suggested potential barriers to adoption of BMPs such as fear, water availability, and drought (Ohlenbusch \& Harner, 2003; Ohlenbusch \& Hartnett, 2000). However, these have not been explored in research. Existing research has, however, looked at many characteristics of BMP adopters. When Oklahoma stocker cattle producers were studied, operation size, income dependency on the operation, and working off the farm all positively affected the likelihood a producer knew how to set stocking rates at recommended levels (Johnson et al., 2010). Producers who depended entirely upon cattle for their income were $10.2 \%$ more likely to be knowledgeable about setting stocking rates. This study also showed that producers who utilized wheat as a forage perceived stocking rate to be critical; these Oklahoma producers would rather stock at lower rates rather than risking inadequate forage (Johnson et al., 2010). Similar results were found for adoption of BMPs in cow-calf production. Dependence upon income from cattle and education were positive indicators for adoption of BMPs. Age was a negative indicator for adopting most BMPs (Ward, Vestal, Doye, \& Lalman, 2008).

Some research has explored motivations for adopting conservation practices and BMPs. Ryan, Erickson, and De Young (2003) found that intrinsic motivations were the strongest motivators towards adopting BMPs. These intrinsic motivators included feeling connected to the land and a desire to maintain fruitful land for future generations; economic motivation was the lowest-rated category. In contrast to long-standing ideas that agricultural producers are primarily motivated by cash, profit, or other extrinsic gains, land-management decisions were driven mainly by personal goals. 
Understanding the motivation behind adoption of BMPs was essential to explain the adoption for each producer (Pannell et al., 2006). Producers utilized a decision-making process to determine whether or not they wanted to adopt a BMP (Pannell et al., 2006). The end decision was based on expectations and perceptions and depended on "the process of learning and experience, the characteristics and circumstances of the landholder within their social environment, and the characteristics of the practice" (Pannell et al., 2006, p. 1408). This process yielded a different kind of knowledge for each producer. Many different factors affected this process: past experiences, scientific knowledge, and cultural factors. The more information producers had available on a particular practice, the more likely they were to adopt it (Prokopy, Floress, Klotthor-Weinkauf, \& Baumgart-Getz, 2008).

In a study surveying Louisiana beef producers, the highest percentage of non-adopters felt the practices, i.e. grassed waterways, rotational grazing, and nutrient management, were not relevant to their operations (Gillespie et al., 2007). The second most common reason for non-adoption was a lack of familiarity with BMPs; information about BMPs still had not reached all producers. It was likely that these reasons overlap, in that many of these producers lacked an overall understanding of BMPs and, therefore, how BMPs could be applied on his or her operation leading to a lack of motivation to adopt them. Producers with lower BMP adoptions also tended to have less contact with Extension services (Gillespie et al., 2007). The number of producers who chose not to adopt BMPs because of cost was relatively low. A substantial number of producers simply did not adopt because they preferred not to (Gillespie et al., 2007). This phenomenon has yet to be explained.

Past research suggests government policies aiming to change producer behavior should be developed based upon the motivations of the producers in specific areas (Greiner, Patterson, \& Miller, 2009). Many of these motivations have yet to be fully understood. Understanding these motivations and the reasons producers choose not to adopt would make tailoring programs easier, therefore, making programs or policies more likely to be adopted (Greiner et al., 2009). Understanding mental models and motivations behind a producer's management strategy could help understand how producers make choices (Russell \& Bewley, 2013).

\section{PURPOSE AND OBJECTIVES}

The purpose of this study was to determine the barriers and benefits producers faced in the process of choosing whether or not to adopt BMPs for grazing systems, the second step in CBSM. The following research questions guided the study:

RQ1: What are the barriers to the adoption of BMPs in grazing systems?

RQ2: What are the benefits to the adoption of BMPs in grazing systems?

\section{METHODS}

\section{Sample and Measures}

In order to address the research questions, qualitative, semi-structured interviews were conducted with 42 beef cattle producers in Kansas and Oklahoma in the summer of 2014. Participants were recruited initially through Extension agents and snowball sampling was used after initial participant interviews. The purposive sampling frame sought to interview producers who had varying levels of adoption in order to get a clear picture of the adoption or non-adoption in the area. Interviews were conducted at each participant's location of choice. These locations included pickup tailgates, county Extension offices, farm kitchens, local restaurants, and oilfields.

The questioning route was designed to guide participants through the research questions in a way that was more relatable to the participant and was helpful to researchers while ensuring consistency between interviews as recommended by Creswell (2007). Questions were asked in order to gain an in-depth understanding of the producer's operations and 
practices (Rubin, 2005). Participants were asked specific questions about barriers to the adoption of BMPs and how they processed information regarding BMPs. Institutional Review Board approval was obtained before recruitment of participants.

Internal consistency and validity was assured by comparing the interviewer's notes, assistant interviewer's notes, and participants' recorded and transcribed responses. The notes by the primary interviewer consisted of handwritten notes on hardcopies of the interviewer's guide for each interview. The assistant interviewer took field notes while the interviews were taking place. All data were collected from interviews via audio recorders and from the interviewers' notes, creating an audit trail. This audit trail served as a description for the research that took place from start to finish (Flick, 2009). The data were transcribed by the professional transcription service, TranscriptionStar (Diamond Bar, CA). All identifying information was removed for confidentiality purposes, and each participant was given a pseudonym. Participants were also assigned a level of adoption by the interviewer and assistant interviewer. Many factors were considered when assigning BMP levels. Those factors included the adoption of rotational grazing, prescribed burning, and watering systems. The interviewer and assistant interviewer discussed each producer to determine their relative level of adoption. The protocol was reviewed by a panel of experts for face and content validity. The experts included professors from agricultural communications, agronomy, and animal science.

\section{Analysis}

The researcher first listened to each interview to confirm the transcribing was done correctly by the professional transcription service and made edits to family names and created the pseudonyms. The software Nvivo 10 was used to code each interview using the constant comparative method. Codes are labels attached to words or phrases within qualitative data to give description or meaning (Bhattacharya, 2007). While coding interviews, the researcher compared it with previous interviews that had been coded. The comparison between interviews was based upon memory and did not require looking back for every comparison (Glaser, 1965). Codes were then sorted into categories of related codes. These categories of codes were sorted by word or concept similarities. For example, each limiting factor was grouped together under a parent code. Those categories were then used to establish themes (Bhattacharya, 2007). Themes were then reviewed and confirmed with the assistant interviewer, who was present at every interview, to increase credibility and validity. All barriers and benefits mentioned in more than one interview are reported, with major themes being identified as those that were mentioned in at least half the interviews (21) (Ray, Baker, \& Settle, 2015).

Participants' operations were sorted into sizes of small, medium, and large, based on the designations from the 2012 Census of Agriculture. One to 49 head of cattle were classified as "small," 50 to 499 head of cattle were classified as "medium," and 500 or were was classified as "large". Land area that ranged from 1 to 139 acres were classified as "small," 140 to 999 acres as "medium," and 1,000 or more as "large". These classifications were based purely upon information volunteered by each producer. There were no specific questions asked about farm or herd size.

The level of adoption of BMPs of each producer's operation was determined by the interviewer and assistant interviewer. When determining the level of adoption many factors were considered such as: adoption of rotational grazing, alternative forages, introduced grass, watering systems, and cover crops. Producers' practices were compared to university-recommended BMPs. High adopters used all or nearly all BMPs, medium adopters used some BMPs, and low adopters used one or none of the BMPs. The interviewer and assistant interviewer discussed each producer to determine their level of adoption. In this study, there were 14 high adopters, 18 medium adopters, and 10 low adopters 


\section{FINDINGS}

\section{RQ1: What Are the Barriers to the Adoption of BMPs in Grazing Systems?}

To explore the barriers associated with the adoption of BMPs, participants were asked questions related to the challenges they face in grazing strategies. Interview responses yielded the following themes: water availability and quality deters producers from adopting BMPs; leasing and renting land presents unique challenges, particularly in Oklahoma; and other limiting factors, like school land, exist for adopting BMPs. Oklahoma school lands are government-owned lands that are leased to producers with the proceeds going towards the support of public schools in the State (Hainer, 1893).

\section{Water availability and quality deterred producers from adopting BMPs.}

Art, a medium-sized Kansas producer with a high level of adoption, mentioned algae-infected ponds as a limiting factor for utilization and rotational pasture grazing.

Big pond down here at the bottom of the hill up until last year we had quite a bit of, about three years of bluegreen algae in that pond. And so, that was limiting that pasture as far as use on it. We have since got rid of it, got some rain, got it filled back up and so it will hopefully be all right.

Blake, a large Kansas producer with a medium level of adoption, mentioned the lack of a watering system as a major barrier to an ideal rotational grazing system.

You know in this country, if you - unless you have a watering system you have to work with what the Lord provides for you and it hasn't been much. So a lot of your rotational grazing might not be exactly what you want to do; it's what you can do... It's been tough these last five years...I don't have a watering system.

Caleb, a large Oklahoma producer with a high level of adoption, said water was the biggest limiting factor from continuing his existing rotational grazing strategy in his operation. "Number one, there's no water. The ponds had all dried up." Andy, a large Kansas producer with a low level of adoption, shared the sentiment. "A lot of it is on moisture, and how much regrowth I've got on it from the year before...I was hauling water since January... We had cleaned ponds out." Blake, a large Kansas producer with a medium level of adoption, was limited by drought. "I have a few places that are watered but without good pond water, it's just hard on what your rotation has been in the past." Cal, a medium-sized producer from Oklahoma with a low level of adoption, also struggled with water and worked hard to acquire it for his herd to continue his implementation of rotational grazing.

I suppose water supply on some of that would be a big factor. You know, having access to get them to water. We have dug several ponds, dug ponds out or had a couple on trial and error basis whether they hold water or not.

\section{Leasing and renting land presented unique challenges, particularly in Oklahoma.}

While both Kansas and Oklahoma producers expressed challenges and barriers related to renting or leasing land, there were distinct differences separated by state lines. Oklahoma had unique challenges related to school-land leases. Kansas does not have that system, but producers still struggled with barriers associated with leased land. The theme of leased land presenting challenges for producers in both states, broke down into two sub-themes: a lack of lease land and a lack of control of leased land.

\section{Lack of Land}

Adam, a large producer from Kansas with a high level of adoption, saw a distinct difference between renting grass for cows and stockers. "It's very hard for guys to rent cow grass," because of the higher quality of grass and extended grazing season needed for cows. Without having access to grass resources, BMPs cannot be adopted. He also said that 
absentee landowners were an obstacle for Kansas producers "... dealing with the next-generation land owner, maybe the investment land owner. You know, they just see it as you're taking something off of that ground."

Clyde, a medium-sized producer from Kansas with a medium level of adoption, talked about the unavailability of grass in his area:

And in our area, it's hard to-grass is hard to-you know, it's hard to come by. And if you can find it, it's hard to get it rented. It's not as bad now as it was a few years ago, but until just the last couple of years, not only that you have to compete with other people that had cattle, the recreational use on grass is - I mean-and most of the people that want it for recreation have unlimited money.

A lack of land limited the ability to rest pastures from grazing or to implement rotational grazing. If more land had been available to Clyde, he would have implemented these practices.

\section{Lack of Control}

Carter, a large Oklahoma producer with a high level of adoption, discussed the issues with urban landowners and the problems he had.

I leased a new pasture and the people are really concerned about it being overgrazed...the lady asked me, she said "What is the best three months for this native grass to grow?" And I said, well, April, May and June are the primary growth months for the grass. "Well you're not to graze it during those three months." But I don't really like being restricted, you know.

These kind of limitations restricted producers from grazing the way they wanted. Producers mentioned other challenges related to burning, installing watering systems, or other BMPs on leased ground.

Oklahoma school land.

Cliff, a large Oklahoma producer with a medium level of adoption, specifically mentioned leased land as a direct barrier to the adoption of rotational grazing, and described the way school land can affect the choices made by producers.

So [school land leases] kind of dictates how much you can put into it as far as fencing it for rotational grazing or, you know, you hate to go in and spend $\$ 40$ or $\$ 50$ an acre when your rent is $\$ 20$ an acre and you may not have it, you know, down the road.

There were four total producers that leased school land. Three of those producers shared this view.

\section{Adoption of rotational grazing was restricted by many barriers.}

Producers across all regions expressed issues they had with adopting the practice of rotational grazing including infrastructural improvements needed, increased labor demands, and the availability of water. Andy, a large Kansas producer with a low level of adoption, expressed his limitations.

Oh yeah, like rotational grazing. But, our system isn't really set up for that. All those things sound really great if it sets up and works for you, but the way we're constantly buying cattle, shuffling and sorting cattle, so we don't have a set of cattle that we're gonna move around everywhere. It just doesn't work for us that great.

Caleb, a large producer from Oklahoma with a high level of adoption, said there were reasons other producers may have for not adopting practices.

Why? Average producers, you know, the average producer is older, they don't have the time to do it or they don't have resources to do it, they put their cows out there and wean their calves, take them to the sale barn, you know, those kind of things. 
Journal of Applied Communications, Vol. 101, Iss. 1 [2017], Art. 5

There were also physical boundaries producers identified as issues for adoption of rotational grazing. Cole, a medium-sized Oklahoma producer with a medium level of adoption, talked about the benefit and boundaries associated with rotational grazing. "We try to practice rotation on all pastures except for two where water is an issue where we just can't. Rotation pays for itself." Brett, a medium-sized producer from Kansas with a medium level of adoption, discussed the different kinds of rotational patterns and the boundaries of his operation. "They have five day, 14 and 21 day. They require electric fences, and I just don't have time to check a hot wire."

\section{Time and Labor Constraints}

Time and labor constraints were not considered major themes as not enough producers mentioned each one. However, since the goal of this study was to find the barriers to BMP adoption, all barriers are mentioned. These are categorized as time and labor constraints.

Seven producers mentioned time and labor as a constraint to the adoption of BMPs. Carter, a large Oklahoma producer with a high level of adoption, mentioned time as the reason behind a less intensive rotational system. "I don't have time to go build a thousand electric fences all over the place. And I do rotate my cattle on my native grass but not any intensive system." Brice, a large Kansas producer with a medium level of adoption, echoed this point. "But I just don't have the time to spend with my cattle that maybe some other people that are in this farming might."

Clint, a large Kansas producer with a high level of adoption, discussed that labor and the physical set up of the land, rather than time, limited the adoption of BMPs. However, he also mentioned that perhaps it would not be worth his time either. "Our wheat fields are scattered so the rotation is a little bit lot more work than it be worth probably."

\section{RQ2: What are the benefits to the adoption of BMPs in grazing systems?}

To understand how producers perceived BMPs and the way they are beneficial or relate to resiliency, producers were asked about their practices, practices of other producers, and about how they dealt with drought. Interview responses yielded the theme: BMPs increased the resiliency of operations. Rotational grazing, improved watering systems, and burning practices were all practices that helped operations maintain resiliency.

\section{Rotational Grazing Allowed for Resiliency}

When asked about their practices, producers talked about the justification for their practices. It was evident that those who utilized rotational grazing clearly saw benefits to it. Bruce, a large Oklahoma producer with a high level of adoption, had recently adopted some rotational grazing practices and planned to expand those practices to the rest of his operation.

I grazed nine different pastures ranging in size from a section to 40 acres was probably my smallest, and I saw the benefits from that last year that this year I'm going to do it a lot better, and I'm going to manage it a little more and try to take care of it.

Chuck, a medium-sized producer from Kansas with a high level of adoption, found that rotational grazing made him better at making choices during drought; it was easier to gauge the number of grazing days left on a patch of grass.

And that was [the] big thing about adding paddocks is we had an idea of how many days of grazing we had, prior to putting the paddocks... when we ran out of grass it's just gone you know...I can't judge that just by looking but if you have paddocks, you kind of have an idea, "Okay I know this will last them three days or seven days." You can kind of... have an idea but without that [paddocks] it's just a shot in the dark so for me.

Clark, a medium-sized Oklahoma producer with a medium level of adoption, found rotational grazing to be beneficial when it came to the utilization of grass in his pastures and overall management "...allowed so much better opportunities 
for pasture to recover and not overgraze to the extent that we used to do with everything."

\section{Improved Watering Systems Allowed Producers to be More Resilient}

Producers recognized the benefits to installing improved watering systems in their operations, which is a BMP that can aid in resiliency. Chuck, a medium-sized Kansas producer with a high level of adoption, had recently installed pipeline and planned on installing tanks in his pastures within days of completing our interview.

Clyde, a medium-sized Kansas producer with a medium level of adoption, saw his cattle benefit from the addition of improved watering systems in his operation.

Cattle actually do better on clean water, and then drinking out of some of the ponds and stuff, they get so stale in the middle of the winter...

Clem, a medium-sized Kansas producer with a high level of adoption, had also seen improvement in the health of his cattle from improved watering. "One thing that I didn't mention that the water tanks and everything like that, that has been so beneficial to me. Because my cattle - the health of those cows are so much better with that water than drinking out of a pond."

\section{Burning Practices Enabled Resiliency}

While eight producers mentioned that drought discouraged prescribed burning practices, 23 producers saw the benefits burning could offer their operation. Chris, a medium-sized Kansas producer with a medium level of adoption, burned pasture for the health of the grass:

I had leased this place, and it had a lot of undergrowth on it, it had a lot of brush, a lot of thatch, and I thought it would make it a little healthier situation if we could burn it, and that's why I did it.

Cliff, a large Oklahoma producer with a medium level of adoption, also burned grass "to kind of keep things clean and freshen up pastures." Clint, a large Kansas producer with a high level of adoption, saw a side-by-side comparison of the increased palatability of grass once exposed to fire.

One year, we tried some within the same pasture, we burnt some on one side of the creek and we didn't get some on the other side of the creek. And the old cows, they just kept on that we burned, grazed into the ground. And the other side, they didn't hardly go over there.

Chip, a medium-sized Kansas producer with a medium level of adoption, did not like burning, but saw the benefits, particularly with controlling cedar trees that he burned regularly.

And part of that getting those pastures and that little devil [cedar trees] under control is burning so every three years to four years we burn you know and I really don't like to burn but we do. You just have to; you just have to do it.

Curt, a large Oklahoma producer with a medium level of adoption, also used fire to control brush and saw it as a more profitable and less time-consuming alternative to other forms of eradicating cedars and brush from his pastures.

[We burn] generally to kill the brush...It saves on poisoning; we've got poison which kill the cedars and everything. It's pretty expensive, pretty time consuming, so [instead] we can burn in two hours and if we get a $20 \%$ kill and burn next year, or two years, three years and you haven't dumped \$5,000 in poison. 


\section{CONCLUSIONS, IMPLICATIONS, LIMITATIONS, AND FUTURE DIRECTIONS}

This study sought to identify the barriers and benefits of BMP adoption in grazing systems. Barriers identified in this study were water availability, water quality, leasing and renting land, and skilled labor. Some of these identified barriers confirm what previous studies have suggested (Ohlenbusch \& Harner, 2003; Ohlenbusch \& Hartnett, 2000). The benefits of BMP adoption as expressed by producers who used BMPs on their operations were increased resiliency as a result of rotational grazing, improved watering systems, and burning practices.

Given these barriers to BMP adoption, the implications of this research indicate a need for communication strategies to alleviate barriers and may include facilitating information processing by agricultural producers related to the adoption of BMPs. While one cannot simply communicate more water into the region, farm advisors (i.e. Extension and NRCS) can better communicate the options for improving water accessibility; and the benefits of improved water access and quality may help producers think differently about their options to overcome water availability.

There are many people seeking to communicate with agricultural producers: Extension, NRCS, industry publications, commodity organizations, peers, social media, universities, and other private organizations (i.e. the Noble Foundation). Through the implementation of CBSM, these information sources used by producers could be leveraged to help producers overcome the barriers unique to their operations. These sources have the potential to be instrumental in the strategic behavior change process related to BMP adoption. It is suggested that these influencers be trained in CBSM and work together to promote the adoption of BMPs in grazing.

To promote the adoption of BMPs in grazing, it is suggested that future research address how producers process information related to BMPs and the social constraints associated with the adoption of BMPs. This study focused on BMPs for producers in Kansas and Oklahoma. It is suggested that similar research be conducted in other states.

\section{REFERENCES}

Ray, J., Baker, L. M., \& Settle, Q. (2015). Ask the audience: Determining organizational identity of state extension agency. Journal of Applied Comunication, 99(4), 62-75. Retrieved from http://journalofappliedcommunications.org/images/stories/issues/2015/jac_v99_n4_article5.pdf

Baumgart-Getz, A., Prokopy, L. S., \& Floress, K. (2012). Why farmers adopt best management practice in the United States: A meta-analysis of the adoption literature. Journal of Environmental Management, 96(1), 17-25.

Retrieved from http://www.sciencedirect.com/science/article/pii/S0301479711003598

Bhattacharya, K. (2007). Introduction to qualitative methods in education: A student handbook. Corpus Christi, TX.

Cox, R. (2013). Enviornmental communication and the public sphere (3rd ed.). Thousand Oaks, CA: SAGE Publications.

Creswell, J. W. (2007). Qualitative inquiry and research design (2nd ed.). Thousand Oaks, CA: SAGE Publications, Inc.

Creswell, J. W. (2014). Research design (4th ed.). Thousand Oaks, CA: SAGE Publications, Inc.

Diekmann, F., \& Batte, M. T. (2009). Examining information search strategies of Ohio farmers. Journal of Extension, 47(6). Retrieved from http://www.joe.org/joe/2009december/a8.php

Feather, P. M., \& Amacher, G. S. (1994). Role of information in the adoption of best management practices for water quality improvement. Agricultural Economics, 11, 159-170.

Flick, U. (2009). An introduction to qualitative research (4th ed.). Thousand Oaks, CA: SAGE Publications, Inc.

Gillespie, J., Kim, S. A., \& Paudel, K. (2007). Why don't producers adopt best management practices? An analysis of the beef cattle industry. Agricultural Economics, 36(2007), 89-102.

Glaser, B. G. (1965). The constant comparative method of qualitative analysis. Social Problems, 12(4). Retrieved from http://www.jstor.org/stable/798843?seq=1\#page_scan_tab_contents

Greiner, R., Patterson, L., \& Miller, O. (2009). Motivations, risk perceptions and adoption of conservation practices by farmers. Agricultural Systems, 99(2-3), 86-104. 
Hallahan, K., Holtzhausen, D., van Ruler, B., Vercic, D., \& Sriramesh, K. (2007). Defining strategic communication. International Journal of Strategic Communication, 1(1).

Hainer, B. (1893). Hainer's manual of the Oklahoma school land laws: Rules and regulations governing the leasing of school lands. Guthrie, OK: State Capital Printing Co.

Hurt, C. (2014, August 4). Where will beef herd expansion happen? Agriculture.com. Retrieved from http://www.agriculture.com/news/livestock/where-will-beef-herd-expsion-happen_3-ar44555

Johnson, R. J., Doye, D., Lalman, D. L., Peel, D. S., Raper, K. C., \& Chung, C. (2010). Factors affecting adoption of recommended management practices in stocker cattle production. Journal of Agricultural and Applied Economics, 42(1), 15-30. Retrieved from http://naldc.nal.usda.gov/naldc/download.xhtml?id=41959\&content=PDF

McKenzie-Mohr, D. (2000). Promoting sustainable behavior: An Introduction to community-based social marketing. Journal of Social Issues, 56(3), 543-554. Retrieved from https://web.stanford.edu/ kcarmel/CC_BehavChange_ Course/readings/Mckenzie_socialmarket_2000.pdf

McKenzie-Mohr, D. (2011). Fostering sustainable behavior: An introduction to community-based social marketing (3rd ed.). Gabriola Island, BC Canada: New Society Publishers.

Natural Resources Conservation Services. United States Department of Agriculture. Range \& pasture. (n.d.). Retrieved June 11, 2014, from http://www.nrcs.usda.gov/wps/portal/nrcs/main/national/landuse/rangepasture/

Ohlenbusch, P. D., \& Harner, J. P. I. (2003). Grazing Distribution. Retrieved from Kansas Agricultural Experiment Station Research Reports. Manhattan, KS.

Ohlenbusch, P. D., \& Hartnett, D. C. (2000). Prescribed burning as a management practice. Retrieved from Kansas Agricultural Experiment Station Research Reports. Manhattan, KS.

Ohlenbusch, P. D. \& Watson, S. L. (1994). Stocking rate and grazing management. Retrieved from Kansas Agricultural Experiment Station Research Reports. Manhattan, KS.

Pallack, M. S., Cook, D. A., \& Sullivan, J. J. (1980). Commitment and energy conservation. Applied Social Psychology Annual, 235-253.

Pannell, D. J., Marshall, G. R., Barr, N., Curtis, A., Vanclay, F., \& Wilkinson, R. (2006). Understanding and promoting adoption of conservation practices by rural landholders. Australian Journal of Experimental Agriculture, 46(11), 1407-1424. Retrieved from http://www.publish.csiro.au/?paper=EA05037

Patton, D., \& Blaine, T. (2001). Public issues education: Exploring extension's role. Journal of Extension, 39(4).

Paudel, K. P., Gauthier, W. M., Westra, J. V., \& Hall, L. M. (2008). Factors influencing and steps leading to the adoption of best management practices by Louisiana dairy farmers. Journal of Agricultural and Applied Economics, 1(April), 203-222.

Prokopy, L. S., Floress, K., Klotthor-Weinkauf, D., \& Baumgart-Getz, A. (2008). Determinants of agricultural best management practice adoption: Evidence from the literature. Journal of Soil and Water Conservation, 63(5), 300-311. http://doi.org/10.2489/jswc.63.5.300

Rahelizatovo, N. C., \& Gillespie, J. M. (2004). The adoption of best-management-practices by Louisiana dairy producers. Journal of Agricultural and Applied Economics, 36(1), 229-240. Retrieved from http://ageconsearch. umn.edu/bitstream/43445/2/Rehelizatovo JAAE April 2004.pdf

Rubin, H. J. (2005). Qualitative interviewing: The art of hearing data (2nd ed.). Thousand Oaks, CA: SAGE Publications, Inc.

Russell, R. A. \& Bewley, J. M. (2013). Characterization of Kentucky dairy producer decision-making behavior. Journal of Dairy Science, 96(7), 4751-4758. http://doi.org/10.3168/jds.2012-6538

Ryan, R. L., Erickson, D. L., \& De Young, R. (2003). Farmers' motivations for adopting conservation practices along riparian zones in a Mid-western agricultural watershed. Journal of Environmental Planning and Management, 46(1), 19-37. Retrieved from http://deepblue.lib.umich.edu/bitstream/handle/2027.42/83699/Ryan,_R.,_D._Erickson_\&_R._De_Young_(2003)_Farmers'_motivations_for_adopting_conservation_practices,_JEPM

Smith, C. M., Peterson, J. M., \& Leatherman, J. C. (2007). Attitudes of Great Plains producers about best management practices, conservation programs, and water quality. Journal of Soil and Water Conservation, 62(5), 97A-103A.

U.S. Department of Agriculture. (2014). 2012 census of agriculture. Washington, D.C. Retrieved fromhttp://www.agcen sus.usda.gov/Publications/2012/Full_Report/Volume_1,_Chapter_1_US/usv1.pdf 
U.S. Department of Agriculture. (2013). U.S. Drought 2012: Farm and Food Impacts. Washington, D.C. Retrieved from http://www.ers.usda.gov/topics/in-the-news/us-drought-2012-farm-and-food-impacts.aspx\#.U16Y88f1 tgN

Vergot III, P., Israel, G., \& Mayo, D. E. (2005). Sources and channels of information used by beef cattle producers in 12 Counties of the Northwest Florida Extension district. Journal of Extension, 43(2). Retrieved from http://www. joe.org/joe/2005april/rb6.php

Vigen, M., \& Mazur-Stommen, S. (2012). Reaching the "high-hanging fruit" through behavior change: How community-based social marketing puts energy savings within reach. Washington, D.C. Retrieved from http:// aceee.org/files/pdf/white-paper/high-hanging-fruit-cbsm.pdf

Wachenheim, C., \& Rathge, R. (2000). Societal perceptions of agriculture. Fargo, ND. Retrieved from http://agecon search.umn.edu/bitstream/23541/1/aer449.pdf

Ward, C., Vestal, M., Doye, D., \& Lalman, D. L. (2008). Factors affecting adoption of cow-calf production practices in Oklahoma. Journal of Agricultural and Applied Economics, 40(3), 851-863.

Wessler, B. (2011). Oklahoma agricultural losses from drought more than \$1.6 billion. Retrieved March 17, 2016, from http://www.cattlenetwork.com/cattle-news/Oklahoma-agricultural-losses-from-drought-more-than-16-billion-129660023.html

\section{ABOUT THE AUTHORS}

Audrey E. H. King is an instructor in agricultural communications and journalism at Kansas State University. She teaches introductory courses and new media technology classes. Her research focuses on Extension, best management practice adoption and environmental issues effecting agriculture.

Dr. Lauri M. Baker is an associate professor in agricultural communications and journalism at Kansas State University where she is the co-creator of the Center for Rural Enterprise Engagement which focuses on new media marketing research to improve the economic viability of rural communities.

Dr. Peter J. Tomlinson is an assistant professor in agronomy at Kansas State University. Peter is an Extension specialist on environmental quality. His research focuses on air, water, and soil quality. 